\title{
EDUCAÇÃO AMBIENTAL E SUSTENTABILIDADE: UMA INTERVENÇÃO EMERGENTE NA ESCOLA
}

Fernanda Rodrigues da Silva Souza ${ }^{1}$

Resumo: A sociedade atual possui desafios complexos e necessita de ações coletivas a fim de redefinir as relações produtivas, cultural e social resultando uma vivência sustentável. O objetivo deste artigo é analisar um projeto de Educação Ambiental que a empresa Vale realiza em parceria com a Emef Eber Louzada Zippinotti em Vitória (ES). É um trabalho que visa desenvolver a consciência ambiental dos estudantes deixando um legado positivo para as gerações futuras. Proporciona aos envolvidos práticas sustentáveis e incentiva proteção e conservação do meio ambiente. A metodologia utilizada envolve dinâmica de grupo, trilha ecológica, aula teórica e pesquisa.

Palavras-chave: Meio Ambiente. Sustentabilidade; Educação Ambiental; Conscientização.

\section{Abstract: Abstract}

Today's society has complex challenges and requires collective action in order to redefine productive, cultural and social relations resulting in sustainable living. The objective of this article is to analyze an environmental education project that the Vale company carries out in partnership with Emef Eber Louzada Zippinotti in Vitória (ES, Brazil). It is a work that aims to develop students' environmental awareness leaving a positive legacy for future generations. It provides stakeholders with sustainable practices and encourages protection and conservation of the environment. The methodology used involves group dynamics, ecological track, theoretical class and research.

Keywords: Environment, Sustainability; Environmental Education; Awareness.

\footnotetext{
1 Faculdade Vale do Cricaré. E-mail: bricioenanda@gmail.com
} 


\section{Introdução}

Os espaços de interações sociais são propícios ao engajamento e a concepção de ações coletivas. Com isso, o ambiente escolar se destaca como centro de atividades e relações que devem ser estimuladas para ações emancipatórias do consumismo e capitalismo. De acordo com Política Nacional de Educação Ambiental. Lei 9597/99:

Art. 2ำ A Educação Ambiental é um componente essencial e permanente da educação nacional, devendo estar presente, de forma articulada, em todos os níveis e modalidades do processo educativo, em caráter formal e não-formal.

Ações desenvolvidas no espaço escolar devem ser estimuladoras de sustentabilidade local e regional interferindo diretamente nos aspectos sociais e culturais. A educação deve cumprir o papel de mediadora no processo de construção da cidadania responsável, na consciência coletiva de finitude dos recursos e na urgência de se conhecer os potenciais naturais da sociedade. Conforme a Lei 9795/1999:

Entendem-se por Educação Ambiental os processos por meio dos quais o indivíduo e a coletividade constroem valores sociais, conhecimentos, habilidades, atitudes e competências voltadas para a conservação do meio ambiente, bem de uso comum do povo, essencial à sadia qualidade de vida e sua sustentabilidade.

Neste artigo é feita uma análise de um projeto de Educação Ambiental realizado no Parque Botânico da Vale em Vitória (ES), envolvendo a turma do sexto ano da Emef Eber Louzada Zippinotti com o objetivo de proporcionar aprendizado e promover mudança de atitudes dos estudantes em prol do desenvolvimento sustentável. $\mathrm{O}$ trabalho se divide em quatro partes. A primeira apresenta uma discussão sobre biodiversidade, água, ar e energia. No segundo encontro são realizadas dinâmicas baseadas nos pilares da Unesco de Educação para o Século XXI (Conhecer, ser, fazer e conviver). A terceira parte é a realização de uma trilha ecológica no Parque Botânico da Vale. E a última etapa é a pesquisa participativa considerando as complexidades do ambiente escolar e suas implicações sociais culminando na elaboração de um projeto elaborado pelos estudantes enquadrado nos preceitos da Educação Ambiental.

Para Alessandra Galli, Educação Ambiental como Instrumento para o Desenvolvimento Sustentável, Juruá Editora, 2008, p. 21, ID:20890: 
$\{. .$.$\} "A Educação Ambiental concebida como instrumento para o$ desenvolvimento sustentável deve enfatizar que o crescimento econômico - parâmetro ilusório - deve estar baseado na noção de sustentabilidade socioambiental, a qual, por sua vez, envolve a noção de bom convívio entre desenvolvimento social, desenvolvimento econômico e proteção ambiental, garantindo assim a perenidade da vida em todas as suas formas."

\section{Sustentabilidade}

O conceito de desenvolvimento sustentável foi proposto em 1987 pela Comissão Mundial do Desenvolvimento e Meio Ambiente formada em 1984 pela ONU. Em 2002 na cúpula sobre desenvolvimento Sustentável realizada em Joanesburgo considera avanços epistemológicos como inclusão da sustentabilidade como um componente essencial.

Somente a partir da Conferência Rio 92, a Agenda 21 destaca a responsabilidade dos países desenvolvidos na crise ambiental mundial e solicita a todos a participação de forma igualitária. Responsabilizando a todos em esfera política e social. Essa "igualdade "de responsabilidade é equivocada pois mesmo que países pobres e suas populações excluídas façam mau uso de seus recursos, a maior responsabilidade será daqueles que detém o poder econômico.

Desta forma todos os povos da terra devem sentir responsáveis pelo futuro do planeta suscitando ações interiores que desencadeiem um planeta sustentável. O diálogo dentro da escola e as ações coletivas têm sido referenciados como fortes aliados por uma proposta sustentável.

O projeto de Educação Ambiental da Vale desenvolvido na Emef Eber Louzada Zippinotti mostra a educação como instrumento de reformulação das relações homem-ambiente. Para esta análise foram estruturados cinco pontos de discussão: biodiversidade, água, ar, energia e resíduo. Através de momentos de estudos no Parque Botânico da Vale e sobre estes pontos foi elaborado e executado um questionário a fim de somar a tese de que pela complexidade das relações, uma ação baseada na participação dos diversos atores envolvidos em um projeto local repercute em uma área de maior atuação, atingindo além dos muros da escola.

A relevância deste projeto de Educação Ambiental para o planeta deve ser iniciada pela afirmação de que estabelecer mudanças em pequenos grupos fará com que atinjam posteriormente grupos maiores.

Para analisar a percepção ambiental dos diversos estudantes na participação dessa ação coletiva e os efeitos na construção do sujeito coletivo destacando os aspectos percepção de mudanças de envolvimento, relevância do projeto para a escola e para os estudantes. Segundo a Conferência das Nações Unidas sobre o Meio Ambiente e Desenvolvimento (Rio De Janeiro, RJ, 1992) 
$\{\ldots\}$ As perspectivas de um futuro de escassez e de grandes desequilíbrios socioambientais apontam para a necessidade urgente de atitudes que valorizem o meio e todas as suas formas de vida. É fundamental: • Reduzir bruscamente nossas fontes poluidoras, sejam estas de resíduos sólidos, líquidos ou gasosos; - Minimizar nossos desperdícios, reciclar e reaproveitar ao máximo os recursos já explorados; - Preservar e conservar ambientes naturais para garantirmos a manutenção de serviços ambientais de inestimável importância como, estabilidade climática, qualidade dos recursos hídricos, de solo e de ar; - Modificar nosso atual modelo de desenvolvimento econômico e encontrar o caminho para um modelo socialmente mais justo, ecologicamente mais saudável e economicamente viável (INSTITUTO PARANAENSE DE DESENVOLVIMENTO ECONÔMICO E SOCIAL - IPARDES, 2001, p.260).

Foram aplicados questionários ao final do projeto nas turmas dos 6ㅇ $\mathrm{A}$ B. Os resultados positivos na percepção do ambiente pelos estudantes reforçam o sucesso do objetivo proposto. Um total de $90 \%$ dos estudantes envolvidos respondeu o questionário destacando como positiva a participação no projeto e a aquisição de conhecimento em Educação Ambiental que levarão para além da escola.

Mudanças no processo ensino aprendizagem foram observadas ao longo do projeto, atendendo as características peculiares de cada turma. Foi necessário articular teoria com prática, além de adotar metodologia diferenciada visando estimular pesquisar e aumentar o conhecimento sobre questões ambientais.

O sucesso do projeto foi garantido mediante a ação participativa dos envolvidos, consenso e sentimento de apropriação pelo grupo. Vale ressaltar que nos anos 80 iniciou-se uma mudança paradigmática na prática de desenvolvimento e gestão de recursos naturais com base na valorização do conhecimento local e essas mudanças culminaram nos anos 90 em diversas iniciativas de envolvimento social.

Alguns educadores que sempre se mostraram avessos a atividades lúdicas e inovadoras sentiram motivação e participaram com empenho superando as expectativas iniciais e ressaltando a importância da busca por novos desafios. Um docente na sociedade contemporânea para superar a inércia precisa de condições motivadoras e libertadoras que podem ser articuladas com outros docentes.

As discussões e debates articulados na atividade e no cotidiano escolar foram mais prazerosos e a formalização do conhecimento em diversas disciplinas foram enriquecidas. A dimensão social foi ampliada a partir do conhecimento que os estudantes levaram da escola para casa, utilizando também para melhoria da relação da família com o meio ambiente. 
Os questionários aplicados traziam questões pertinentes ao projeto e avaliava o grau de satisfação dos envolvidos, o nível de aprendizagem que cada encontro propiciava aos estudantes e o que seria possível modificar após a execução do projeto na prática para melhorar a proteção ao meio ambiente adquirindo práticas sustentáveis. Ressaltamos que o questionário está em anexo.

projeto de Educação Ambiental foi apresentado para a professora de Ciências da Emef "ELZ" através de slides no momento do planejamento da disciplina (Figura 1). E tem como objetivo geral desenvolver a consciência ambiental das comunidades deixando um legado positivo para as gerações do presente e do futuro.

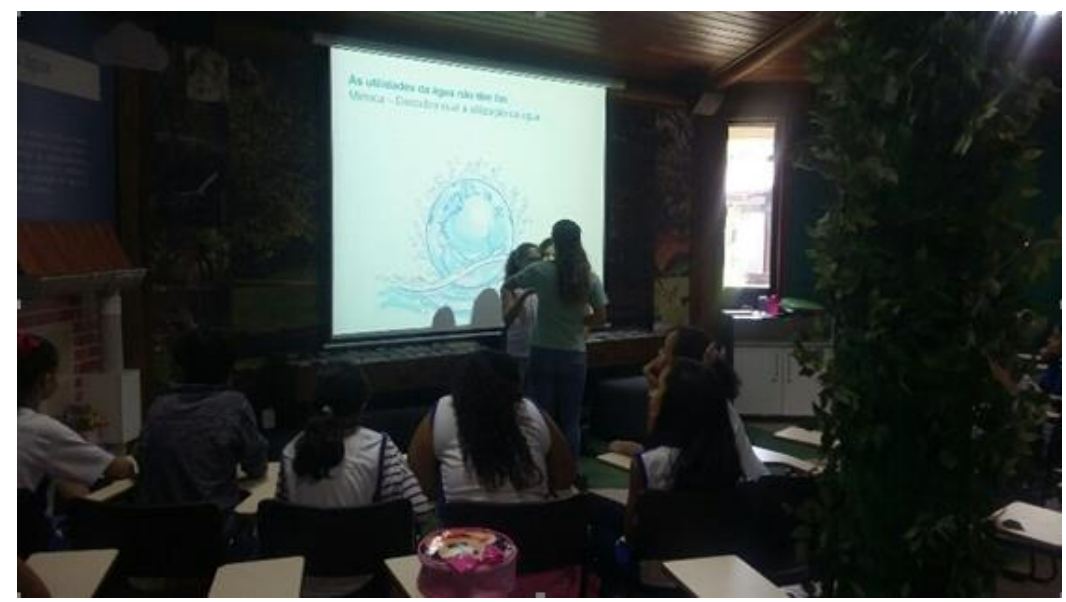

Figura 1: momento de explicação sobre a utilização da água.

A motivação inicial para participação no projeto Educação Ambiental da Vale foi a ideia de proporcionar aprendizado com o objetivo de promover a mudança de atitudes em prol do desenvolvimento sustentável dos estudantes.

Considerando a principal motivação que levou ao engajamento do projeto é possível verificar uma sensibilidade ambiental acentuada.

A segunda intenção destaca a Educação Ambiental como processos e por meio dos quais o indivíduo e a coletividade constroem valores sociais, conhecimentos, habilidades, atitudes e competências voltadas para a conservação do meio ambiente, bem de uso comum da população, essencial a sadia qualidade de vida e sua sustentabilidade.

Em relação aos estudantes e docentes diretamente envolvidos inicialmente foram escolhidas as turmas que desenvolveriam o projeto. Em seguida os encontros no Parque Botânico da Vale foram agendados e realizados (Figura 2). E durante o desenvolvimento do projeto foi trabalhada a concepção de que Educação Ambiental é componente essencial e permanente na educação nacional, devendo estar presente em todos os níveis e modalidades do processo. 


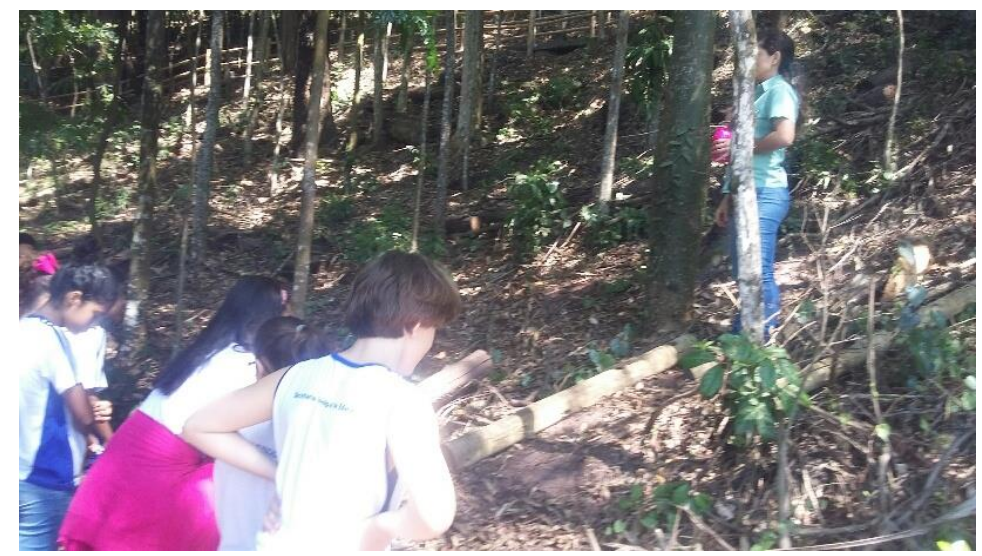

Figura 2: trilha ecológica.

\section{Conclusões}

O artigo relata a realização da análise do projeto Educação Ambiental na Vale e destaca a pesquisa e ações coletivas colaborando para a gestão sustentável de recursos naturais e incentiva o processo ensino aprendizagem. Dentre as ações realizadas durante a execução do projeto destaca-se uma importância em aspectos sustentáveis culminando em solidariedade, pesquisa, mudança de visão do ambiente e participação coletiva.

$O$ projeto mostrou que ações pequenas podem dinamizar toda a comunidade escolar. A Educação Ambiental é componente essencial e permanente da educação nacional, devendo estar presente de forma articulada em todos os níveis e modalidades.

As turmas 60 A e B durante o projeto apresentaram um grau de entendimento e maturidade acima do esperado sobre todos os temas trabalhados. Muitos estudantes levaram para si o objetivo geral do projeto e consequentemente passarão adiante todo conhecimento adquirido ao longo do projeto. Em alguns momentos, um ou outro demonstrou pouco interesse, mas rapidamente foi realizada intervenção para convencimento da necessidade em trabalhar os temas e a resposta dos estudantes foi muito positiva.

Após a realização do projeto no dia- a- dia da escola foi observado pequenas mudanças no âmbito da Educação Ambiental. Principalmente com as turmas envolvidas. Observou-se inferior quantidade de lixou no pátio da escola e práticas reais de sustentabilidade.

Muitos estudantes estimulados pelo projeto buscaram juntos aos professores envolvidos desenvolver oficinas de material reciclado e também realizar o descarte correto do lixo dentro da escola e em suas casas. 


\section{Agradecimentos}

Aos estudantes que nos proporcionaram momentos excelentes de aprendizagem durante a execução do projeto.

\section{Referências}

BRASIL. Ministério da Educação. Política Nacional de Educação Ambiental. Lei 9597/99, 1999,

GALLI, A. Educação Ambiental como instrumento para o desenvolvimento sustentável. 1. ed. Curitiba, PR: Juruá, 2008. 307 p.

INSTITUTO BRASILEIRO DO MEIO AMBIENTE E DOS RECURSOS NATURAIS RENOVÁVEIS. Geo Brasil 2002: perspectivas do meio ambiente no Brasil. Brasília: IBAMA, 2002. 447 p.

INSTITUTO PARANAENSE DE DESENVOLVIMENTO ECONÔMICO E SOCIAL - IPARDES. Agenda 21. Curitiba: IPARDES, 2001. 260 p. 